\title{
EXPERIMENTAL METHOD FOR SPRAY VELOCITY FIELD PREDICTION MODEL IN PRESSURE SWILL ATOMIZERS
}

\author{
E. J. J. Souza ABSTRACT \\ and M. J. J. S. Ponte \\ Universidade Federal do Paraná \\ Departamento de Engenharia Mecânica \\ Bairro Jardim das Américas \\ CP. 19011, CEP: 81531-980 \\ Curitiba, Paraná, Brasil \\ andiogenes@ufpr.br \\ Pressure swill atomizers are widely used in engineering as an effective \\ device for vaporization and liquid mass transfer in physical or chemical \\ processes. Among many applications those atomizers are used in modern \\ fuel injection systems for spark engines. An even fuel and air mixture may \\ increase the overall engine performance by higher efficiency and low flue \\ gas emissions. In applied atomization, one of the most important \\ characteristics is the spray velocity field prediction. Droplet sizing models \\ are also important, but they are relatively popular on books and papers. By \\ the other hand spray velocity field prediction and profile is relatively rare. \\ This work focus on the prediction of the velocity field of pressure swirl \\ atomize by means of an experimental approach and applied statistics. For \\ the spray measurements this study used a non-intrusive, quantitative method \\ by Laser Doppler Interpherometry (LDI) for the spray velocity field and \\ droplet sizing. Also four models for the film thickness calculation at \\ atomizer discharge are compared considering their statistical significance.
}

Keywords: fuel injection, pressure swill atomizer, spray velocity field

\section{NOMENCLATURE}

$\mathrm{d}_{0} \quad$ Orifice diameter $\quad[\mathrm{m}]$

$\mathrm{d}_{\mathrm{n}} \quad$ Internal air diameter at orifice $\quad[\mathrm{m}]$

$\mathrm{t}_{0} \quad$ Liquid film thickness at orifice [m]

$\mathrm{A}_{0} \quad$ Orifice area $=\pi\left(\mathrm{d}_{0}^{2} / 4\right) \quad\left[\mathrm{m}^{2}\right]$

$A_{n} \quad$ Air nuclear area $=\pi\left(\mathrm{d}_{\mathrm{n}}^{2} / 4\right) \quad\left[\mathrm{m}^{2}\right]$

$\mathrm{L}_{\mathrm{b}} \quad$ Break up length $\quad[\mathrm{m}]$

$\mathrm{U}_{0} \quad$ Liquid velocity at orifice outlet $\quad[\mathrm{m} / \mathrm{s}]$

$\mathrm{U}_{\mathrm{g}} \quad$ Droplet velocity at position $\left(\mathrm{Z}, \theta_{\mathrm{g}}\right)[\mathrm{m} / \mathrm{s}]$

$\mathrm{p} \quad$ Liquid pressure gauged upstream the orifice [N/m2]

$\mathrm{d}_{\mathrm{g}} \quad$ Droplet Sauter mean diameter- SMD [m]

Y Droplet position (radial) [m]

$\mathrm{Z} \quad$ Droplet position downstream [m]

\section{Greek symbols}

$\alpha \quad$ Spray angle rad

$\rho_{\mathrm{a}} \quad$ Air density $\quad\left[\mathrm{kg} / \mathrm{m}^{3}\right]$

$\rho_{\mathrm{L}} \quad$ Liquid density $\quad\left[\mathrm{kg} / \mathrm{m}^{3}\right]$

$\sigma \quad$ Surface tension $\left[\mathrm{kg} / \mathrm{s}^{2}\right]$

$\mu \quad$ Liquid dynamic viscosity

$\theta \quad$ Spray semi angle rad

$\theta_{\mathrm{g}} \quad$ Droplet semi angle position

$\Theta_{\mathrm{g}}=\operatorname{arc}$ tangent $(\mathrm{Y} / \mathrm{Z}) \quad \mathrm{rad}$

\section{INTRODUCTION}

The performance of an internal combustion engine depends on several factors related to the machine and engine operation. Most of the improvements achieved in decreasing emissions and increasing performance in either diesel or spark engines are due to the optimization of the injection systems. The nozzle design plays an important role of the overall spray quality. An even and well distributed fuel and air mixture at the engine inlet is a common goal of vehicle manufacturers worldwide. Modern market demands two fundamental performance features: energy conservation and emission control, even for GHG (greenhouse gases). In fact the electronic fuel injection technology gave a tremendous improvement in spark engine performance surpassing the old carburetor definitively.

In conventional spark engines the fuel is sprayed in the intake manifold at the mixing zone, just a few centimetres upstream of the intake valve. Taylor (1988) says that as important as the air-fuel flow rates is the mixture quality. The sprayed mixture should be as even and uniform as possible in order to promote good droplet vaporization and, on some spots, a controlled droplet penetration.

Conventional injection systems typically employ special pressure swill atomizers. Such an injector generates a hollow-cone, large angle spray of droplets. The liquid flows through the discharge orifice with angular velocity achieved by helical grooves which is internally machined upstream the orifice. The spray formed has three discrete velocity 
components in axial (main), tangential and radial direction.

One of the most important features in a fully developed spray is the droplet size and velocity. As a matter of fact droplet penetration and vaporization are related to the droplet size and velocity. Important research and development of sprays and the fuel injection performance seek the size and velocity determination. In order to improve the air/ fuel mixture performance the droplet size prediction is mandatory at certain distance " $Z$ " downstream the orifice discharge. One of the main approaches for estimating the spray the droplet size is the experimental study of deterministic models. The spray velocity field is also important because different spray zones have their own mean velocity. In a hollow cone spray the mass flow distribution and droplet momentum allows to preview the liquid penetration at the engine inlet valve.

Some authors such as Lefebvre and Yule (1996) studied extensively pressure-swill atomizers. Other important contributions such as Chryssakis (2003) and Souza (2009) have shown a comparative evaluation of the calculation models for predicting the spray mean diameter (SMD). The droplet size estimation are more present in papers and books, however the spray velocity and even more the velocity field where $\mathrm{v}=\mathrm{v}(\mathrm{X}, \mathrm{Y}, \mathrm{Z})$ are more rare.

Among all the necessary parameters for determination of the spray flow and spraying performance the calculation of the liquid film thickness in the annular flow at discharge orifice is mandatory. To be able to succeed with experimental models however, it is necessary to calculate such film thickness at the discharge orifice. According to Lefebvre (1989) there are four models for calculating the estimative thickness, respectively proposed by Simmons and Harding, Risk and Lefebvre, Griffin and Muraszew, and finally Griffen and Risk.

This paper shows an experimental approach for the spray studies using statistical correlation between the operating conditions and the droplet velocity field. Also the four models for annular film calculation have been evaluated upon a set of statistical criteria based on significance and variance analysis. Furthermore by using the same approach it was possible elect the calculation model that best fits the size and velocity field for this kind of pressure swill atomizers.

\section{SPRAY IN A PRESSURE SWILL ATOMIZERS}

In pressure swill atomizers used in fuel injection systems the spray cone has a typical morphology as shown in Fig.1. There is a conventional picture of the spray and the three main zones of the spray and droplets formation. The spray may be identified by distinct regions of instability following the liquid from the tip up to fully developed spray.

The liquid passes through the discharge orifice and so it gets axial and angular acceleration due to internal grooves. The liquid angular acceleration becomes tangential component of velocity just downstream the orifice. Also the liquid gains axial and radial velocity leading to a conical shape. By the mass conservation the liquid film thickness becomes thinner as the spray expands. The flow momentum generates disturbances that breaks the surface tension and viscous forces leading to film break up to ligaments. At the beginning of zone 2 unstable ligaments come up, just downstream the film break up. Due to certain vibration instability the ligaments break up results in zone 3 where drops and finally droplets are formed.

Because the angular velocity the liquid film flows through the orifice creating an annular section and an air empty core. The discharge factor is naturally low, around 0.3 to 0.4 as stated by Lefebvre (1989). The experiments performed in this study showed and the operating conditions set, the average discharge factor was 0.32 .
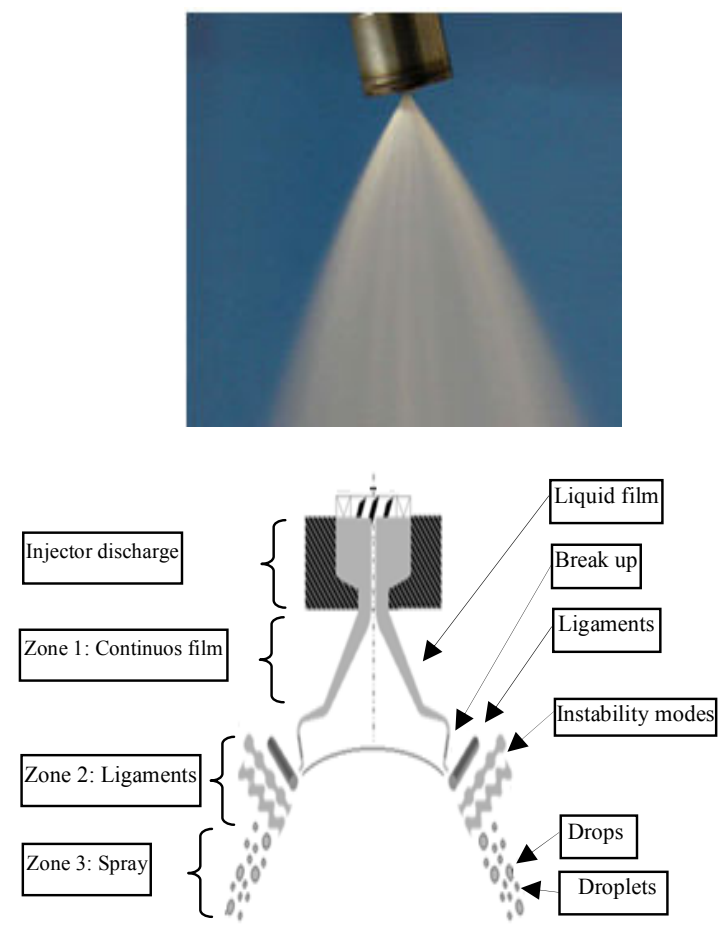

Figure 1. Pressure swill atomizer used in fuel injectors and the spray - morfology jector Ter conical spray and morphology.

\section{APPROACH}

\section{Spray Velocity Field}

Considering the injector geometry at the orifice section the effective annular flow area demands specific calculation models and peculiar fluid mechanics equations. In despite of the injector geometry simplicity the hydrodynamics of the atomization process at those atomizers is complex 
and highly dissipative (Lefebvre, 1989). In this work the details of the internal geometry of the tip will only be considered for the liquid film calculation purposes. It has been assumed that the injector has a fixed, typical geometry of commercial injectors.

The figure 2 shows the conical spray diagram and the related variables of the spray cone.
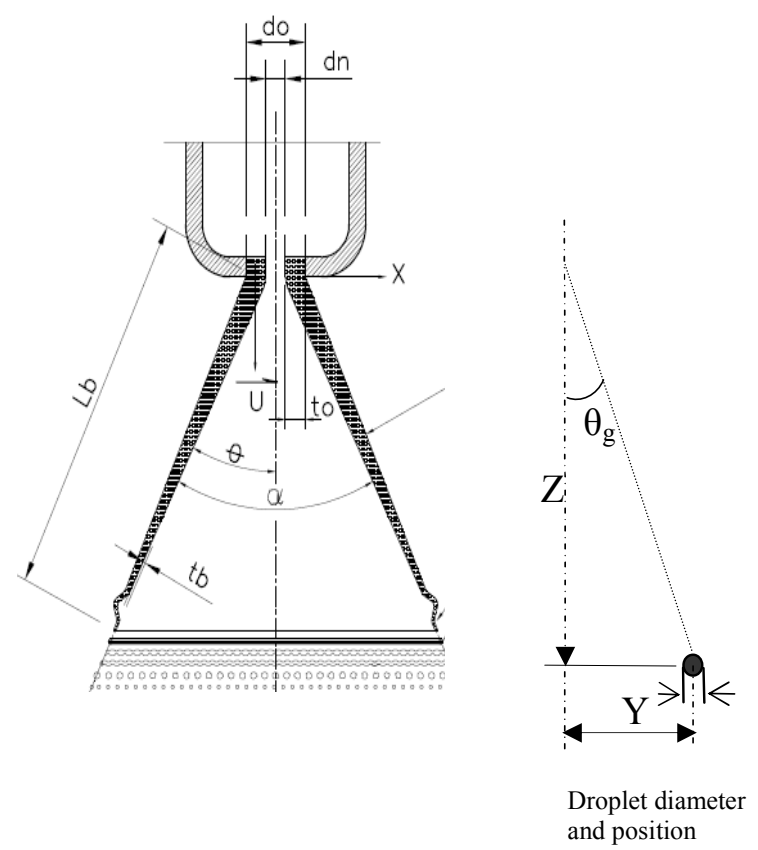

Figure 2. Conical spray.

From the continuity equation

$$
\dot{m}_{L}=U_{0} \rho_{L} \cdot\left(A_{0}-A_{n}\right)
$$

The calculation of the liquid film thickness $\mathrm{t}_{0}$ at the orifice discharge is

$$
t_{0}=\frac{d_{0}-d_{n}}{2}
$$

And, the " $\mathrm{X}$ " ratio is

$$
X=\frac{A_{n}}{A_{0}}=\left(\frac{d_{n}}{d_{0}}\right)^{2}
$$

Considering the film thickness $\mathrm{t}_{0}$,

$$
X=\frac{\left(d_{0}-2 . t_{0}\right)^{2}}{d_{0}^{2}}
$$

The "flow number"

$$
F_{N}=\frac{\dot{m}{ }_{L}}{\sqrt{\Delta P \cdot \rho}{ }_{L}}
$$

And the discharge factor

$$
C d=\frac{\dot{m}_{L}}{\dot{m}_{\text {teórica }}}
$$

Besides the relations of the atomizer flow, many other quantities are involved in the atomization process. Lefebvre (1987) says that the main features of the spray as its diameter and velocity field depend on the atomizer geometry and the liquid flow characteristics. Authors such as Welty (1984) confirm such assertion. Thus it is possible to establish a set of flow variables and geometry data that represents the atomization phenomena. In this work the main spray dependent variable is the droplet velocity $U_{g}$. According to Lefebvre (1989) the main quantities involved in the atomization process is presented in equation (7). Assuming the mean velocity at a specific position in the spray as the main dependent variable $\mathrm{U}_{\mathrm{g}}=\mathrm{U}_{\mathrm{g}} \cdot(\mathrm{X}, \mathrm{Y}, \mathrm{Z})$ or in a conical spray $\mathrm{U}_{\mathrm{g}}=\mathrm{U}_{\mathrm{g}} \cdot\left(\mathrm{Z}_{\mathrm{g}} ; \theta_{\mathrm{g}}\right)$ or $\mathrm{U}_{\mathrm{g}}=\mathrm{U}_{\mathrm{g}} \cdot\left(\mathrm{Z} ; \theta_{\mathrm{g}}\right)$. The correlation function " $\mathrm{f}$ " may be written as follows:

$$
\begin{aligned}
& U_{g}=f\left(U_{0} ; \rho_{a} ; \rho_{L} ;\right. \\
& \left.\theta_{g} ; d_{0} ; p ; \mu ; \sigma ; z_{g}\right)
\end{aligned}
$$

Where the function "f" shown in equation (7) correlates the dependent and the independent variables.

A spray approach using only fluid mechanics equations is very complex because the phenomena of liquid fragmentation is strongly dissipative (Lefebvre, 1989) and so it is necessary to set a strong boundary assumptions in order to reach the Navier-Stokes' equation solution. Nowadays the use of computation fluid dynamics CFD for the atomization studies gives results of difficult validation. So an experimental approach becomes a good alternative method.

In this paper the statistical approach demanded a test plan and the observation of the dependent and independent variables observation in order to seek correlations with acceptable significance in engineering. However a test plan with several levels in all the variables is a time consuming process since it requires an extensive test plan. A good choice is to organize the correlation between the variables by dimensional analysis according to the " $\pi$ " Buckingham theorem. Dimensionless groups are created that condense the variables and eliminate errors related to size. Using the theorem to the variables can be organized as follows:

$$
\begin{aligned}
& \frac{U_{g}}{U_{0}}=f\left(\frac{\rho_{a}}{\rho_{L}} ; \frac{z}{d_{0}} ; \frac{p}{U_{0}^{2} \cdot \rho_{L}} ;\right. \\
& \left.\frac{U_{0} \cdot \rho_{L} \cdot d_{0}}{\mu} ; \frac{\rho_{L} \cdot U_{0}^{2} \cdot d_{0}}{\sigma} ; \frac{\theta_{g}}{\theta}\right)
\end{aligned}
$$


The dimensionless groups in the correlation function (8) shows the main dependent variable, the ratio of the droplet velocity " $\mathrm{U}_{\mathrm{g}}$ " and the liquid velocity " $\mathrm{U}_{0}$ " through the atomizer orifice. By the other hand all the independent variables appear as dimensionless numbers such as ratios for densities, the axial position, the Euler, Reynolds and Weber number and finally the position angle of the droplet. For nomenclature purposes all dimensionless numbers can be renamed to "P" parameters, starting with the dependent variable $\mathrm{Ug} / \mathrm{U}_{0}=\mathrm{P} 1$ and the dependent parameters as P2, P4 and so on, as shown in equation (8a). The parameter $\mathrm{P}_{3}$ has been is the droplet diameter ratio, not shown in this paper.

$$
P_{1}=f\left(P_{2} ; P_{4} ; P_{5} ; P_{6} ; P_{7} ; P_{8}\right)
$$

As the atomization phenomena are strongly dissipative and so the correlation function "f" presented on equation 8 a was initially assumed to be nonlinear. The proposed correlation model was the equation (9) where "c2" to "c8" are exponents of dimensionless parameters to be found. Then the correlation model was based upon a multiple nonlinear regression with six exponents (c2 and $\mathrm{c} 4$ to c8) to be determined.

$$
\begin{aligned}
& P 1=1 \cdot(P 2)^{c 2} \cdot(P 4)^{c 4} \cdot(P 5)^{c 5} \\
& \cdot(P 6)^{c 6} \cdot(P 7)^{c 7} \cdot(P 8)^{c 8}
\end{aligned}
$$

It was necessary to create a test database by measuring all operating data upstream the injector tip, calculating the dimensionless figures and the measurement of droplet size. After determining the exponents the resulted correlation has been evaluated regarding the significance criteria and the variance analysis - ANOVA.

In several dimensionless parameters the discharge velocity $U_{0}$ seems to be the most important variable since it appears in several groups.

With the measurements of liquid mass flow rate at the orifice and the continuity equation (1) it is possible to calculate the discharge velocity using the diameter of air core or indirectly the film thickness t0 by equation (2) . This variable can be calculated by mathematical models proposed by some authors, considering that the direct measurement at the orifice section is quite complex, as commented by Chryssakis (2003).

\section{Liquid Film Thickness $\mathbf{t}_{\mathbf{0}}$ Calculation}

A major study on calculating the thickness t0 was presented by Lefebvre (1996) and later a review by Chryssaquis (2003), which showed comparisons of calculation models available, based on an experimental database. However
Chryssaquis'research was based on generic atomizer, not a set of engine injectors. In addition, he has several reservations about the models whereas the database used was based on tests with water only. Finally the author recommends further studies of the calculation models and experimental validation for selecting the most appropriate one. The four main calculation models are:

1 Equation of Muraszew \& Griffen

$$
\left(\frac{A_{P}}{D_{S} d_{0}}\right)^{2}=\frac{\pi^{2}}{32}\left(\frac{(1-X)^{3}}{X^{2}}\right)
$$

Where $A_{p}$ is the area of internal ports (grooves) upstream the orifice, as they generate rotation (swirl) and Ds the equivalent diameter of these ports, upstream of the discharge orifice and $\mathrm{X}$ is the ratio of areas, given by equation (3).

2 Equation of Simmons e Harding, from experimental data,

$$
t_{0}=0,00805 \cdot \frac{\sqrt{\rho_{L}} \cdot F_{N}}{d_{0} \cdot \cos \theta}
$$

3 Equation of Risk e Lefebvre

$$
t_{0}=2,7 \cdot\left[\frac{d_{0} \cdot F_{N} \cdot \mu}{\sqrt{p_{L} \cdot \rho_{L}}}\right]^{0,25}
$$

4 Equation of Griffen e Risk

$$
0,09 \cdot\left(\frac{A_{P}}{D_{S} d_{0}}\right)\left(\frac{D_{S}}{d_{0}}\right)^{0,5}=\frac{(1-X)^{3}}{X^{2}}
$$

In order to achieve the model that best fits the injector atomization this work was based upon a statistical approach. Then the analysis criteria were based on the correlation of the independent variables upstream the discharge and the measurements of the droplet velocity at position " $Z$ " and semi-angle $\theta_{\mathrm{g}}$. This approach, however, demanded the formation of a database of tests by varying the pressure, the relative position of the spray region and the test liquids.

The database demanded an appropriate test plan, which offers measurement liability of the independent variables and, above all, the dependent variable. For the independent variables the measurements have been taken using conventional methods and for the velocity measurements was used laser based PDI- Phase Doppler Interferometry.

Finally the selection criteria were based on the statistical significance of the correlation in order to choose the best model for the application. 


\section{TEST PLAN}

The test plan focused on the variability of the quantities involved in equation (8) and the dependent variable such as velocity in a certain position of the spray $U g=U g(\theta, Z)$. The spray has been assumed axisymmetric and the flow is continuous at a steady state. For the droplet sizing the $P D I$ laser system kept the laser beans crossing at a specific reading volume at the position $(\theta, z)$ for 10 seconds per run. During that period of time an average of $10^{4}$ droplets have been measured in the spray. No studies of transient effects have been carried out.

For each test the liquid film thickness has been calculated at the orifice using the four models presented in 3.2.1 to 3.2.4. They led to four different film thicknesses $t_{0}$. With each calculated value of thickness was possible to calculate the velocity of the fluid at the discharge $\mathrm{U}_{0}$. The independent variables of equation (7) had four related factors: the average velocity, the test liquid, pressure and position of the droplet. In each of these factors were related to independent variables. The levels were different for each variable, as shown in table 2 below:

Table 1. Test Plan - Independent Variables.

\begin{tabular}{|ll|}
\hline Injector & $\begin{array}{l}\text { Main variable: orifice diameter } \mathrm{d}_{0}= \\
0.568 ; 0.584 ; 0.585 ; 0.598 ; 0.606 \text { and } \\
\end{array}$ \\
\hline Liquids & $\begin{array}{l}\text { Main variables: } \rho \mathrm{mm} ; \rho \mathrm{L} ; \sigma ; \mu \text { (nine } \\
\text { levels) }\end{array}$ \\
\hline Pressure & $\begin{array}{l}\text { Main variable: pressure }=1,2,4,6 \\
\text { and } 8 \mathrm{MPa} \text { (five levels) }\end{array}$ \\
\hline $\begin{array}{l}\text { Droplets } \\
\text { SMD } \\
\text { relative } \\
\text { position } \\
d_{g}=d_{g}(\theta, z)\end{array}$ & $\begin{array}{l}\text { Main variable: } \theta \\
\text { For } \mathrm{Z}=40 \mathrm{~mm} ; \mathrm{Y}(4,8,12,16,18, \\
\end{array}$ \\
\hline
\end{tabular}

The test plan assumed a set of test liquids with different physical properties as shown in Table 3. A total of nine liquids referring to the respective levels of the test plan in Table 2, including: four types of gasoline, two types of ethanol and water-based mixtures in order to give properties variability. The values of $\rho \mathrm{a}, \rho \mathrm{L}, \mu$ and $\sigma$, at different temperatures were measured in laboratory using, respectively, an Anto Parr densimeter, a Kruss tensometer and an Herzog viscometer according to ASTM "American Society for Testing and Materials" standard methods. In each test the conditions were logged upstream the injector, especially pressure and temperature. The physical properties were obtained by interpolation of measured values.

\section{SPRAY TEST RIG}

The test database demanded the construction of a spray test rig with flow meters, pressure gauges, thermometers and the Phase Doppler Interferometry system. Moreover, due to the use of several test liquids, including hydrocarbon fuels and other compounds, it was necessary to use the test bench with safety devices. The spray measuring device used an enclosure with inert gas purge for the spray discharge to avoid hazardous mixtures.

Table 2. Test liquids.

\begin{tabular}{|c|c|c|c|c|c|}
\hline \multirow[b]{3}{*}{ Ident. } & \multicolumn{5}{|c|}{ Liquid Data (as laboratory measurements) } \\
\hline & \multirow{2}{*}{$\begin{array}{c}\text { Density } \\
\begin{array}{c}\rho \\
\left(\mathrm{kg} / \mathbf{m}^{3}\right)\end{array}\end{array}$} & \multicolumn{2}{|c|}{ Viscosity } & \multicolumn{2}{|c|}{ Surface tension } \\
\hline & & $\begin{array}{c}\mathrm{v} \\
\left(10^{\circ} \mathrm{C}\right) \\
(\mathrm{cSt})\end{array}$ & $\begin{array}{c}\mathrm{v} \\
\left(25^{\circ} \mathrm{C}\right) \\
(\mathrm{cSt})\end{array}$ & $\begin{array}{c}\sigma \\
\left(10^{\circ} \mathrm{C}\right) \\
(\mathrm{mN} / \mathrm{m})\end{array}$ & $\begin{array}{c}\sigma \\
\left(25^{\circ} \mathrm{C}\right) \\
(\mathrm{mN} / \mathrm{m})\end{array}$ \\
\hline FL1 & 687.8 & 0.72 & 0.63 & 20.80 & 19.20 \\
\hline FL2 & 699.0 & 0.77 & 0.66 & 20.40 & 18.40 \\
\hline FL3 & 806.8 & 2.28 & 1.60 & 23.20 & 22.10 \\
\hline FL4 & 795.1 & 1.95 & 1.46 & 24.50 & 23.40 \\
\hline FL5 & 997.84 & 1.31 & 1.00 & 74.22 & 72.74 \\
\hline FL6 & 1149.2 & 14.55 & 7.47 & 54.50 & 54.30 \\
\hline FL7 & 1124.1 & 7.62 & 4.27 & 55.50 & 56.60 \\
\hline FL8 & 750.17 & 0.80 & 0.67 & 22.40 & 21.90 \\
\hline FL9 & 752.03 & 1.09 & 0.67 & 23.10 & 21.50 \\
\hline
\end{tabular}

FL1 - Gasoline 1

FL2 - Gasoline 1

FL3 - Ethanol 1

FL4 - Ethanol 2

FL5 - Water

FL6 - Water $(40 \%)+$ Glycerin $(60 \%)$

FL7 - Water $(50 \%)+$ Glycerin $(50 \%)$

FL8 - Gasoline 3

FL9 - Gasoline 4

The bench tests focused on the generation of sprays and so variables and parameters involved in the phenomenon could be measured and compared with the average droplet velocity. Figure 3 shows the flowchart of the bench, including droplet measurements with the PDI laser system.

\section{MEASUREMENTS}

About 470 tests have been performed varying the six independent variables shown in the correlation function (8). Especially the dimensionless numbers Euler, Reynolds and Weber, respectively represented by P5, P6 and P7 have been measured in the test runs. The Euler number ranged from 0.76 to 3.08 and so passing by the unit. The Reynolds number varied from 995 to 46,000 and so from laminar to turbulent flow and finally the Weber number varied from 0.9 to 60, also passing by the unit. This variability is especially useful for the analysis of flow regimes and evaluation force scale involved in the phenomenon of fragmentation. The results were compiled into a spreadsheet containing the valid tests. A reprint of the illustrative database shown in Table 4. 


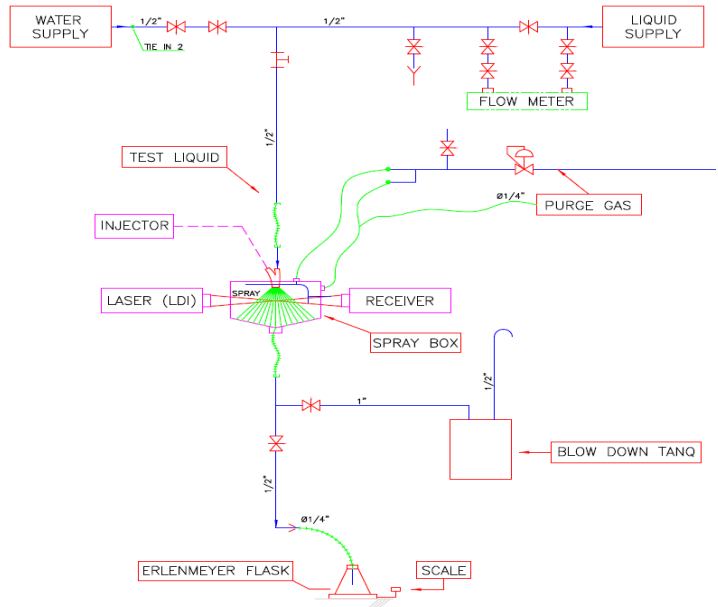

Figure 3. Atomization test rig- flow sheet.

Table 3. Reprint Database.

\begin{tabular}{|c|c|c|c|}
\hline$\frac{U_{g}}{U_{0}}$ & $\frac{\rho_{a}}{\rho_{L}}$ & $\frac{d_{g}}{d_{0}}$ & $\frac{Z}{d_{0}}$ \\
\hline $\mathbf{U}_{\mathbf{g}} / \mathbf{U}_{\mathbf{0}}$ & $\boldsymbol{\rho}_{\mathbf{a}} / \boldsymbol{\rho}_{\mathbf{L}}$ & $\mathbf{d}_{\mathbf{g}} / \mathbf{d}_{\mathbf{0}}$ & $\mathbf{Z} / \mathbf{U}_{\mathbf{0}}$ \\
\hline $\mathbf{P 1}$ & $\mathbf{P 2}$ & $\mathbf{P 3}$ & $\mathbf{P 4}$ \\
\hline 0.6832 & 0.0011 & 0.1129 & 68.49 \\
\hline 0.6366 & 0.0011 & 0.1131 & 68.49 \\
\hline 0.6025 & 0.0011 & 0.1138 & 68.49 \\
\hline 0.5643 & 0.0011 & 0.1135 & 68.49 \\
\hline 0.6980 & 0.0011 & 0.1136 & 68.49 \\
\hline 0.7363 & 0.0011 & 0.1145 & 68.49 \\
\hline 0.7496 & 0.0011 & 0.1087 & 68.49 \\
\hline 0.7378 & 0.0011 & 0.1107 & 68.49 \\
\hline 0.7362 & 0.0011 & 0.1127 & 68.49 \\
\hline 0.7233 & 0.0011 & 0.1130 & 68.49 \\
\hline 0.7029 & 0.0011 & 0.1140 & 68.49 \\
\hline 0.7156 & 0.0011 & 0.1152 & 68.49 \\
\hline 0.6652 & 0.0011 & 0.1142 & 68.49 \\
\hline
\end{tabular}

\begin{tabular}{|c|c|c|c|}
\hline$\frac{P}{U_{0}^{2} \cdot \rho_{L}}$ & $\frac{U_{0} \cdot \rho_{L} \cdot d_{0}}{\mu}$ & $\frac{U_{0}^{2} \cdot \rho_{L} \cdot d_{0}}{\sigma}$ & $\frac{\theta_{g}}{\theta}$ \\
\hline $\mathbf{E u}$ & $\mathbf{R e}_{\mathbf{0}}$ & $\mathbf{W \mathbf { e } _ { 0 }}$ & $\mathbf{\theta}_{\mathbf{0}} / \boldsymbol{\theta}$ \\
\hline $\mathbf{P 5}$ & $\mathbf{P 6}$ & $\mathbf{P 7}$ & $\mathbf{P 8}$ \\
\hline 1.7016 & 7373.76 & 0.9556 & 0.70 \\
\hline 1.6993 & 7399.20 & 0.9582 & 0.75 \\
\hline 1.7021 & 7367.37 & 0.9451 & 0.80 \\
\hline 1.7047 & 7338.91 & 0.9330 & 0.85 \\
\hline 1.7055 & 7329.54 & 0.9261 & 0.64 \\
\hline 1.7090 & 7290.45 & 0.9156 & 0.59 \\
\hline 1.6761 & 7668.48 & 0.9906 & 0.59 \\
\hline 1.6741 & 7691.24 & 0.9969 & 0.64 \\
\hline 1.6719 & 7717.79 & 0.9996 & 0.70 \\
\hline 1.6694 & 7748.26 & 1.0033 & 0.75 \\
\hline 1.6697 & 7744.47 & 1.0022 & 0.80 \\
\hline 1.6675 & 7771.26 & 1.0049 & 0.85 \\
\hline 1.6665 & 7782.93 & 1.0033 & 0.89 \\
\hline
\end{tabular}

For the calculation of each model proposed in equations (10) to (13) a specific database like Table 3 has been created. These data were undergone to data reduction and analysis of variance. In order to get the best equation for calculating $\mathrm{t}_{0}$ it was necessary to process the database tailored for each equation. The criteria for choosing the best one was, at first, the coefficient of multiple determination "R2" and the evaluation of $p$-value compared to the level of significance "alpha" of 5\%. With the choice of the best proposal was possible to deepen the statistical evaluations of the regression model. The comparative results are presented in Table 5 as follows:

Table 4. Comparison of models for droplet diameter by several proposals for the calculation of $t_{0}$.

\begin{tabular}{|c|c|c|c|c|}
\hline Diameters & $\begin{array}{l}\text { Expo } \\
\text { nents }\end{array}$ & Estimate & $\begin{array}{c}\text { Standar } \\
\text { d error }\end{array}$ & t-value \\
\hline \multirow{6}{*}{$\begin{array}{l}\text { Simmons \& } \\
\text { Harding } R^{2} \\
=\mathbf{0 , 9 3 5 4}\end{array}$} & c2 & 0.287682 & 0.044912 & 6.4055 \\
\hline & c4 & 0.280809 & 0.077399 & 3.6281 \\
\hline & c5 & 0.260518 & 0.127956 & 2.0360 \\
\hline & c6 & -0.125624 & 0.016001 & -7.8512 \\
\hline & c7 & -0.175047 & 0.016579 & -10.5586 \\
\hline & c8 & 0.655797 & 0.037585 & 17.4485 \\
\hline \multirow{6}{*}{$\begin{array}{c}\text { Risk \& } \\
\text { Lefebvre } \mathbf{R}^{2} \\
=0,9456\end{array}$} & c2 & -0.21520 & 0.066976 & -3.2131 \\
\hline & c4 & 0.32532 & 0.070942 & 4.5858 \\
\hline & c5 & -1.32789 & 0.150021 & -8.8514 \\
\hline & c6 & -0.46838 & 0.042858 & -10.9287 \\
\hline & c7 & -0.19837 & 0.013567 & -14.6212 \\
\hline & c8 & 0.65433 & 0.034167 & 19.1509 \\
\hline \multirow{6}{*}{$\begin{array}{c}\text { Griffen \& } \\
\text { Muraszew } \\
\mathbf{R}^{2}=\mathbf{0 , 9 3 1 2}\end{array}$} & c2 & 0.49212 & 0.057595 & 8.5444 \\
\hline & c4 & 0.12359 & 0.074744 & 1.6536 \\
\hline & c5 & -1.02212 & 0.154377 & -6.6210 \\
\hline & c6 & -0.06160 & 0.014919 & -4.1289 \\
\hline & c7 & -0.21766 & 0.016581 & -13.1272 \\
\hline & c8 & 0.63728 & 0.037973 & 16.7827 \\
\hline \multirow{6}{*}{$\begin{array}{c}\text { Griffen \& } \\
\text { Risk } R^{2}= \\
0,9432\end{array}$} & c2 & 0.51904 & 0.054057 & 9.6016 \\
\hline & c4 & 0.20816 & 0.067560 & 3.0812 \\
\hline & c5 & -1.23229 & 0.156134 & -7.8925 \\
\hline & c6 & -0.09736 & 0.013769 & -7.0706 \\
\hline & c7 & -0.22605 & 0.014864 & -15.2078 \\
\hline & c8 & 0.68990 & 0.034487 & 20.0046 \\
\hline
\end{tabular}

\begin{tabular}{|c|c|c|c|c|}
\hline Diameters & $\begin{array}{l}\text { Expo } \\
\text { nents }\end{array}$ & p-value & $\begin{array}{c}\text { Lo. Conf } \\
\text { Limit } \\
(\text { alpha }= \\
0,05))\end{array}$ & $\begin{array}{c}\text { Up. Conf } \\
\text { Limit } \\
(\text { alpha }= \\
0,05)\end{array}$ \\
\hline \multirow{6}{*}{$\begin{array}{c}\text { Simmons \& } \\
{\text { Harding } R^{2}}^{2} \\
=\mathbf{0 , 9 3 5 4}\end{array}$} & c2 & 0.000000 & 0.199415 & 0.375948 \\
\hline & c4 & 0.000319 & 0.128695 & 0.432923 \\
\hline & c5 & 0.042344 & 0.009043 & 0.511993 \\
\hline & c6 & 0.000000 & -0.157071 & -0.094178 \\
\hline & c7 & 0.000000 & -0.207630 & -0.142465 \\
\hline & c8 & 0.000000 & 0.581931 & 0.729663 \\
\hline \multirow{6}{*}{$\begin{array}{c}\text { Risk \& } \\
\text { Lefebvre } \mathbf{R}^{2} \\
=0,9456\end{array}$} & c2 & 0.001411 & -0.34684 & -0.08356 \\
\hline & c4 & 0.000006 & 0.18589 & 0.46476 \\
\hline & c5 & 0.000000 & -1.62275 & -1.03304 \\
\hline & c6 & 0.000000 & -0.55262 & -0.38415 \\
\hline & c7 & 0.000000 & -0.22504 & -0.17170 \\
\hline & c8 & 0.000000 & 0.58718 & 0.72149 \\
\hline \multirow{6}{*}{$\begin{array}{c}\text { Griffen \& } \\
\text { Muraszew } \\
\mathbf{R}^{2}=\mathbf{0 , 9 3 1 2}\end{array}$} & c2 & 0.000000 & 0.37893 & 0.605303 \\
\hline & c4 & 0.098910 & -0.02329 & 0.270481 \\
\hline & c5 & 0.000000 & -1.32550 & -0.748737 \\
\hline & c6 & 0.000043 & -0.09092 & -0.032280 \\
\hline & c7 & 0.000000 & -0.25025 & -0.185079 \\
\hline & c8 & 0.000000 & 0.56266 & 0.711909 \\
\hline
\end{tabular}




\begin{tabular}{|c|c|c|c|c|}
\hline & c2 & 0.000000 & 0.41280 & 0.625278 \\
\cline { 2 - 5 } Griffen \& & $\mathbf{c 4}$ & 0.002189 & 0.07539 & 0.340937 \\
\cline { 2 - 5 } Risk R & $\mathbf{c 5}$ & 0.000000 & -1.53914 & -0.925446 \\
\cline { 2 - 5 } $\mathbf{0 , 9 4 3 2}$ & $\mathbf{c 6}$ & 0.000000 & -0.12442 & -0.070297 \\
\cline { 2 - 5 } & $\mathbf{c 7}$ & 0.000000 & -0.25526 & -0.196834 \\
\cline { 2 - 5 } & $\mathbf{c 8}$ & 0.000000 & 0.62213 & 0.757682 \\
\hline
\end{tabular}

Evaluating the results and considering the criteria of the coefficient of multiple determination "R2" the top performers were from Griffen and Risk and Risk and Lefebvre models, with a little difference. But making an analysis of variance of the regression using the Risk and Lefebvre model all the "c" exponents are significant. The largest $p$-value is 0.0014 for the exponent $\mathrm{c} 2$, but still well below the level of significance an alpha-cut, adopted as 0.05 or $5 \%$. Also the prediction model for the droplet mean diameter, according to the constraints and assumptions of this work, is shown by the following equation.

$$
\begin{aligned}
& \frac{U_{g}}{U_{0}}=\left(\frac{\rho_{a}}{\rho_{f}}\right)^{-0,5836} \cdot\left(\frac{z}{d_{0}}\right)^{-0,5077} \\
& \cdot E u^{-0,4819} \cdot \mathrm{Re}^{-0,2077} \cdot \\
& W e^{-0,2953} \cdot\left(\frac{\theta_{g}}{\theta}\right)^{0,4239}
\end{aligned}
$$

Comparing the measurements results with the predicted values of droplet average velocity from equation (14) there is excellent consistency, as shown in the figure (4).

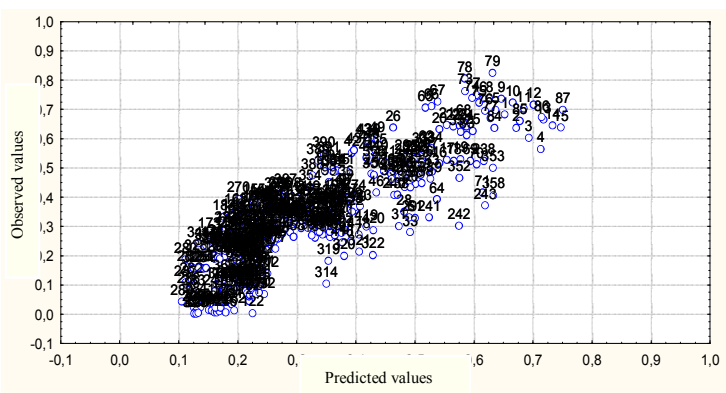

Figure 4. Correlation between the predicted and observed $\mathrm{U}_{\mathrm{g}} / \mathrm{U}_{0}$ values.

Finally, the regression model for the spray droplet velocity was undergone to an analysis of variance. Table 6 below shows the results for the P3 model is, the diameter ratio $\mathrm{d}_{\mathrm{g}} / \mathrm{d}_{0}$, the dependent variable

Table 5. Variance analysis for the equation (14)

\begin{tabular}{|c|c|c|c|}
\hline & $\begin{array}{c}\text { Sum of } \\
\text { Squares }\end{array}$ & $\begin{array}{c}\text { Degrees of } \\
\text { freedom }\end{array}$ & $\begin{array}{c}\text { Mean } \\
\text { Squares }\end{array}$ \\
\hline Regression & 55,47215 & 6 & 0,2453 \\
\hline Residual & 3,8846 & 434 & 0,00895 \\
\hline Total & $\mathbf{5 9 , 6 5 5 8 1}$ & $\mathbf{4 4 0}$ & \\
\hline
\end{tabular}

\begin{tabular}{|l|c|c|c|}
\hline & F - value & P - value & \\
\hline Regression & 1032,91 & 0,00 & \\
\hline
\end{tabular}

The variance analysis indicates the model has good statistical significance. The p-value shows up the regression model has non-zero exponents and so the independent variables have acceptable significance. The quality of fit is evaluated by multiple correlation coefficients squared as follows:

$$
\begin{aligned}
& \mathrm{R}^{2}=\frac{\text { SQregression }}{\text { SQtotal }}= \\
& \frac{55,47215}{59,65581}=0,9298
\end{aligned}
$$

The ratio indicates that the model for the mean droplet diameter is excellent as it explains $92.98 \%$ of the variation, leaving the residue for only $7 \%$. The relationship between a response variable and the explanatory variables measured by the correlation coefficient $\mathrm{R}=0.9642$, which shows that the outcome variable is strongly associated with the explanatory variables.

\section{CONCLUSION}

This study examined fuel injectors commonly used in spark engines, especially fuel injectors with pressure swill atomizers.

According to a statistical approach on a large database, it was possible to correlate the variables involved. Through analysis of variance four models for the liquid film thickness calculation have been evaluated. The best model was the Risk \& Lefebvre equation considering its best results in significance.

Also the paper presents a model for predicting the droplet average velocity of the spray at a certain section downstream the discharge with coordinates $\left(\mathrm{Z} ; \theta_{\mathrm{g}}\right)$ of an axissimetric conical spray. The model with dimensionless variables correlated the injector geometry data and operating conditions.

\section{REFERENCES}

Taylor, C. F., 1988, Análise dos motores de combustão interna. São Paulo: Edgard Blücher, v. 2. (in Portuguese)

Lefebvre, A. H., 1996, Introduction to atomizer and spray technology. Manchester: University of Manchester-UMIST (10 Short course on Atomizer \& Spray Technology).

Yule, A. J., Lefebvre, A.H., Azzopardi, B. J., Turner, J.T., and Jasuja, A. K., 1996, Introduction to atomizer and spray technology. Manchester: University of Manchester-UMIST (10th Short Course on Atomizer \& Spray Technology).

Received: October 07, 2009

Revised: November 07, 2009

Accepted: December 072009 
Chryssakis, C. A., Assanis, D. N., Lee, J., and Nishida, K., 2003, Fuel spray simulation of highpressure swirl-injector for DISI engines and comparison with laser diagnostic measurements, Michigan: University of Michigan.

Souza, E. J. J., 2009, Concepção e desenvolvimento de correlações experimentais para a simulação, controle e otimização de sprays gerados em atomizadores mecânicos-centrífugos; Tese de Doutorado; Programa de Pós Graduação em Engenharia e Ciências dos Materiais da Universidade Federal do Paraná, Curitiba, Brazil. (in Portuguese)

Lefebvre, A. H., 1989, Atomization and sprays. London: Taylor \& Francis (Combustion: An International Series).

Welty, J. R., Wicks, C. E., and Wilson, R. E., 1984, Fundamentals of momentum, heat and mass transfer, $3^{\text {rd }}$ ed., New York: John Wiley \& Sons. 